\title{
Striving for Change: Introducing an Interdisciplinary Approach into the Urban Primary Schools of China
}

\author{
Lan Zou \\ Foreign Language Department, Xihua University \\ Chengdu 610039, China \\ E-mail: lanzou5@163.com
}

\begin{abstract}
In the traditional Chinese curriculum, subjects are learned separately since students start their formal schooling. Students usually neglect the connection among different subjects, which, to some extent, restricts their way of thinking. In order to change the status quo, the focus of this paper is to explore the feasibility of introducing an interdisciplinary approach into the current curriculum of urban primary schools in China. Also, this paper predicts the problems when the interdisciplinary approach is implemented, and provides some suggestions and solutions for school leaders and teachers to adopt.
\end{abstract}

Keywords: Interdisciplinary approach, Curriculum reform, Implementation, Value

\section{The problems of the conventional teaching $\&$ learning style in China}

For decades long, the traditional Chinese curriculum organization has been dominated by the single subject design for decades. Sowell (1996) claims, "The obvious advantage (of this design) is that students studying a single subject learn the content of that subject and the methodologies that authorities in that subject develop and use to organize knowledge" (p. 55). However, even with the increasing specialization in separate subject areas, students often fail to see the connection among them, and store only fragmental knowledge in their heads. As A. Yang (1991) comments, "The subjects included in the curriculum plans are usually selected, organized, taught and evaluated separately without considering interrelations and interactiveness between one another" (p. 23).

Another major trait of the current Chinese curriculum is textbook-based teaching and learning. In China, the curriculum tends to focus on the selective and narrow knowledge of the textbooks. Mak (1998) has observed that textbook knowledge is the focus of Chinese classroom activities (p. 252-254). Many Chinese students simply have no choice about what to learn. Consequently, they are easy to lose their interests in the whole learning process.

2. The on-going curriculum reform and the feasibility of the interdisciplinary approach in the primary schools of China

Having noticing the existing problems in the current curriculum, the State Council is set to complete the curriculum reform in elementary and middle schools nationwide by 2004. 49 new courses in 20 subjects will be implemented in 27 provinces in the coming fall semester. The on-going curriculum reform puts a stress on quality education, which aims at fostering students' innovative capabilities and improving their practical competence. Also, the new curriculum intends to strengthen the links between different subjects as well as the connection between course content and students' real life (http://www.edu.cn/20010831/200906.shtml).

Another noticeable change in the Chinese curriculum reform is the great reduction of the students' workload. 39 textbooks have been banned in the primary and middle schools of China (http://english.peopledaily.com.cn/english/200003/09/eng20000309L101.html). With fewer assignments, students will have more time to engage in the interdisciplinary learning, which largely depends on students' active involvement and the development of their own problem-solving skills.

There are additional two reasons supporting the introduction of interdisciplinary curriculum in primary schools in China. First, students' active attitudes toward learning should be cultivated at the beginning of their formal schooling. Otherwise, they probably become passive knowledge recipients. Some life-long learning skills such as problem-solving and self-thinking skills should be developed as early as possible. Or such important learning capacities will be lost in the traditional teaching and learning style. Second, students in the Chinese primary schools don't have to face so much pressure and fierce competition as students in the secondary schools, where the time and efforts of both teachers and students are devoted to the preparation of National College Entrance Examination (NCEE). There, the adoption of a 
new curriculum, which has not shown any evidence to improve students' scores in NCEE, will be hard to obtain approvals from the school leaders, and will certainly encounter great resistance from the secondary school staff members, parents as well as students themselves.

\section{The rationale and distinctive features of interdisciplinary theory}

Subject matter is widely regarded as the most popular basis for curriculum organization. The interdisciplinary instruction (also known as fused subjects) falls into the category of subject matter designs. But unlike a multidisciplinary approach, or correlated subjects, the individual identities of the courses are lost in an interdisciplinary approach. Campbell and Harris (2001) define an interdisciplinary approach as "connected ways of learning and content from more than one discipline by organizing the curriculum around a central focus" (p. 6).

The famous educationist Howard Gardner's well-known theory of multiple intelligences serves as a strong argument for an interdisciplinary approach. Clearly, this theory urges educators and teachers to try to link the eight intelligences within a curriculum focused on understanding, which is a primary focus of interdisciplinary instruction. A fundamental characteristic of the interdisciplinary approach is to involve students in comprehensive instructional units of study. Wood (2001) defines three unique features for such units: (1).Each interdisciplinary unit focuses on a central theme; (2). Students explore the central theme by using skills and techniques --- ways of knowing --- from a variety of disciplines; (3). The interdisciplinary method places equal emphasis on the mastery of process and content (p. 2).

\section{The possibilities and concerns on the implementation of an interdisciplinary approach}

To implement an interdisciplinary curriculum in the Chinese primary schools will definitely bring about considerable changes into the traditional curriculum mechanics, which has been compartmentalized into separate subjects or disciplines for a rather long time. Sowell (1996) reminds us that "any change to a different purpose would very likely require massive professional development efforts and considerable communication among teachers, students, administrators, and community members" (p. 81). "Three keys to changing the curriculum are time, flexibility, and resources" (Spies, 1997, p. 43).

\subsection{Needs for Skills}

First, the interdisciplinary teaching requires teachers to have an extensive foundation of general knowledge so that they can guide students through interdisciplinary studies. Second, teachers need to have a thorough background in the area of child development and be able to apply their cognitive and affective understanding in their curriculum planning. An awareness of students' individual learning styles such as their thinking and reasoning characteristics can help teachers implement their instruction more effectively for students at different developmental levels. Third, interdisciplinary instruction demands that teachers develop unit and lesson planning skills and classroom management skills. To be skilful planners, they must learn how to create lessons and units that interest and involve their students and how to provide the guidance that students need to pursue their inquiries. Equally important, teachers must learn to manage several different activities simultaneously for a great number of activities usually occur during the implementation of an interdisciplinary unit. Fourth, the interdisciplinary method calls for collaboration among teachers. No matter which option of school collaboration (direct collaboration or indirect collaboration) teachers choose to adopt, classroom teachers need to work cooperatively with professionals with differing informational backgrounds such as special area teachers in art, music, physical education or other experts out of the school environment (Bauwents \& Hourcade 1995, p. 29-39). Thus, some necessary collaborative teaching skills become a must for interdisciplinary teachers to facilitate the whole interdisciplinary process, which will predicatively be a big challenge for Chinese primary school teachers who have long been accustomed to working separately in their own subject areas.

The interdisciplinary approach will be a brand-new curriculum approach for most Chinese primary school teachers compared to the traditional single-subject approach. Mastering the above-mentioned professional knowledge and skills deserves time and efforts. Otherwise, the lack of professional knowledge in this field will add great difficulty to implement the interdisciplinary instruction. In reality, there are two possible ways for the urban primary school teachers to gain the professional knowledge and skills for it. On the one hand, they can conduct a library survey in the school library to find books concerning the curriculum reform and the interdisciplinary teaching methods to read. They can also go to bookstores, especially the foreign language bookstores in their city to look for such books. On the other hand, they can actively engage in the pre-service and in-service trainings, which most Chinese primary schools provide for their teachers' professional development, to listen to lectures given by the education theorists in some Normal Universities.

\subsection{Needs for Planning Time}

Interdisciplinary units involve the teachers of different subjects in examining a topic, issue, or problem from a variety of perspectives. They need a great deal of time to plan the interdisciplinary thematic units. Campbell and Harris asserts (2001), "Administrators and teachers must face the reality that thematic curriculum development is time consuming if they want to reap the benefits of integration" (p. 29). They estimates that, "the time required for a curriculum planning 
team to thoroughly research and develop a theme study is on the average 150 hours, with approximately 20 hours spent in team meetings and around 30 to 40 hours spent by each team member in independent work" (p. 28).

The best preparation for a new school year is summer time. Usually, the Chinese primary school teachers use the summer time to write their curriculum for the new school year independently, and submit it to the school leaders for review nearly one month before the beginning of the new school year. Now in order to effectively implement the interdisciplinary approach, team teachers need to devote their summer time to the intensive interdisciplinary planning. During the summer, interdisciplinary teams are expected to get to know each other, agree on common expectations for students, agree on common expectations for team members and identify individual roles for team members, check class lists, make introductory phone calls to parents and students for preliminary advocacy, decide what will happen the first week to set a positive tone, begin a team calendar of homework assignments and tests, and decide where, how long, and how often to meet during the coming semester. (Spies, 1997, p.43-46). Then, during the new semester, team teachers should plan regular team meetings to share what they teach from week to week, and communicate the reactions of that particular group of children. Based on their genuine understanding of the children's emerging interests and needs, interdisciplinary teachers take the responsibility of constantly refining their curriculum to meet their students' expectations.

\subsection{Needs for Support}

To ensure eventual success in any change in the curriculum, administrative, material, and financial supports are of indispensable importance.

Traditionally, in Chinese primary schools, teachers of different subjects teach the same class of students at different grade levels. These teachers may teach the same group of children as short as one semester or as long as the whole six-year primary school period depending on the school administrative manipulation. Each class has a head teacher who is in charge of everything in their students' learning and in their daily life. Except teaching a particular subject, the head teacher is responsible for collecting reflections from students and teachers of other subjects, and often acts as the agent to facilitate the communication between students and teachers as well as the communication between different subject teachers. However, such communication is intermittent and inconstant. Most often, when they run into real problems, students and other teachers approach the head teacher to report the trouble, and want to get possible solutions from the head teacher. Usually, it is at that moment that the head teacher begins to notice this problem and make an investigation of it. This kind of organizational structure has given rise to high inefficiency in solving problems in primary school students' learning in China.

Evidently, the interdisciplinary approach can avoid such communication inefficiency to a large extent. Interdisciplinary units involve different subject teachers working together constantly. Interdisciplinary teachers must be guaranteed sufficient planning time and meeting time in the school schedule. That is to say, the implementation of an interdisciplinary curriculum means to beak the traditional primary school organizational arrangements, which is far from easy in the bureaucratic educational system of China. To conduct a curriculum reform in a Chinese primary school, you must get the permissions from both the school administrators and the officials in the local Education Bureau who is in charge of these affairs. If the school administrators and the officials cannot envision ways that school and state objectives can be met through interdisciplinary curriculum, they will hesitate to support implementing teachers. Furthermore, since the application of "One-child" policy in the late 1970s, the only child becomes "the little emperor" or "princess" in a Chinese family. Parents pay much more attention to their children's education and their academic achievement than usual to ensure their future success. For many parents, this approach to learning may seem like too much fun and vastly different from the way they were taught. But if they cannot see strong evidence that this new curriculum approach is capable of improving their children's academic performances, they will resist allowing their children to experiment with the new curriculum. When dealing with administrators, local officials, and parents, communication is the key. Implementing teachers should make good preparations for various kinds of unexpected questions and initial resistance from them.

Another concern for interdisciplinary teachers is the availability of resources. Students deserve great literature and require multiple sources of information at an appropriate reading level in order to do research on thematic studies. Therefore, the interdisciplinary teacher should check the available resources before committing to a particular theme. Basically speaking, the school library or the city libraries should be able to provide rich published resources of theme-related materials and guidebooks for interdisciplinary teaching. The students and teachers should have an easy access to the Internet both in school and at home, which proves to be an effective tool in search of valuable information. Or students and teachers can engage in online chat to exchange ideas or post their opinions on a website established for thematic studies. The interdisciplinary teacher also needs convenient media support. Telecommunication equipment, such as videos, television, projectors, should be available for class presentations upon request.

Sufficient numbers of quality resources are essential for thematic lessons and activities. This turns out to be the major reason why I suggest introducing the interdisciplinary approach only in urban areas. There is a huge discrepancy in 
human and educational resources between urban and rural areas in China. In the vast rural areas, most people live in poverty. Rural parents are too poor to send their children to school, which mainly leads to high school dropout rates in these areas. Schools in rural areas are usually poorly equipped. Some primary schools in rural areas consist of mud brick houses built years, decades, or even centuries ago. Let alone other advanced educational equipment and material resources. But in the urban areas of China, schools are often found over-equipped. Urban parents earn much higher salaries than their rural counterparts. Both the urban families and schools are capable of affording the needed resources for the implementation of an interdisciplinary curriculum if they have been convinced of the effectiveness of the new curriculum to the children's academic development.

\section{Values of an interdisciplinary approach to primary school students}

For any change in a curriculum, the first challenging question the planner must answer is: What are the possible benefits to our students? In my understanding, the implementation of an interdisciplinary approach is able to solve some knotty problems Chinese educators and teachers face in the traditional curriculum, and, ultimately, bring advantages to our students in the following aspects.

\subsection{Cultivation of autonomous learning skills}

Instead of being passive recipients, when exploring unit themes, students often use knowledge and skills in different discipline areas to make plans, test their ideas, and make choices about their learning. They will not wait to receive their teachers' decisions and arrangements. In this way, students become more confident in their academic skills such as creative thinking, problem solving, and decision making, and grow as autonomous, independent learners, which is the expected goal of our education.

\subsection{Reduction of students' workload}

Chinese students are often found overwhelmed by homework and assignments. Parents complain that their children have no time to play. At times, students find that what they have learned in a Chinese language class appears later as the content of the Chinese history textbook. In an interdisciplinary approach, in order to avoid unnecessary redundancy and repetition, the team teachers check the school-wide curriculum map, and communicate with each other before they write a workable interdisciplinary plan. Students will benefit from a coordinated calendar of homework and tests.

\subsection{Formation of a less biased viewpoint}

In the conventional textbook-based curriculum, Chinese students are forced to accept the opinion of a single text-book as it is the only resource they can rely on. An interdisciplinary approach exposes students to a greater variety of information resources, which offer them a more rounded, less biased viewpoint, especially in the social studies and science subjects.

\subsection{Benefits to students with poor grades}

In most cases, there is a kind of hierarchy in a Chinese primary school system. Students with higher scores in exams receive praise in the class whereas students who have poor grades are given criticism and discrimination. Often, it is the former category that gains much of the attention from their teachers while the latter ones remain unnoticed for they do not stand out from the crowd. However, when the team teachers plan an interdisciplinary curriculum, they usually make a research on the diverse learning styles of each student. Teachers shift their focus from the usual stress on the logical-mathematical and linguistic intelligences to the development of students' multiple intelligences. They encourage shared, multiple views of each student. In so doing, more students with talents of different areas will get noticed from their teachers. It will do good to the all-round development of each student.

\section{Conclusions}

To sum up, in this paper, I mainly deal with the necessity and possibility of introducing an interdisciplinary approach into the urban primary schools in China. Admittedly, any change at the beginning stage of its implementation will encounter a variety of resistance and, even, rejection. It takes time for people to see its benefits and accept it. To initiate an interdisciplinary curriculum in the Chinese primary schools, the first task is to persuade our teachers to believe in the magic of the new curriculum, thus being willing to invest their time and energy to make the trial to strive for inspiring changes in the new curriculum.

\section{References}

Bauwens, J., \& Hourcade, J. J. (1995). Cooperative teaching: Rebuilding the schoolhouse for all students. Austin, TX: PRO-ED, Inc.

Campbell, D. M., \& Harris, L. S. (2001). Collaborative theme building: How teachers write integrated curriculum. Boston: Allyn \& Bacon.

Curriculum reform to open new courses in Autumn Semester (2001, August). [Online]Available: http://www.edu.cn/20010831/200906.shtml (December 1, 2008) 
Mak, G. C. L. (1998). Classroom management in China: Personalizing groupism. In N. K. Shimahara (Ed.), Politics of classroom life: Classroom management in international perspective (pp. 239-260). New York \& London: Garland Publishing, Inc.

Quality education, focus of China's educational reform: NPC (National People's Congress) (2000, March 9). [Online]Available:

http://english.peopledaily.com.cn/english/200003/09/eng20000309L101.html (December 1, 2008)

Spies, P. (1997). Interdisciplinary teams for high schools. Bloomington, IN: the Phi Delta Kappa Educational Foundation.

Sowell, E. J. (1996). Curriculum: An Integrative Introduction. Englewood Cliffs, NJ: Merrill/Prentice-Hall.

Wood, K. E. (2001). Interdisciplinary instruction: A practical guide for elementary and middle school teachers (2 ${ }^{\text {nd }}$ ed.). Upper Saddle River, NJ: Merrill/Prentice-Hall.

Yang, A. (1991). China's school curriculum reforms in the 1980s: Achievements and problems. Portsmouth, NH: New England Educational Research Organization. (ERIC Document Reproduction Service No. ED333567) 